\title{
Dickkopf-1 induces apoptosis in the JEG3 and BeWo trophoblast tumor cell lines through the mitochondrial apoptosis pathway
}

\author{
HONG CUI, HUAN LI, QIU-LING LI, JING CHEN, QUAN NA and CAI-XIA LIU
}

Department of Obstetrics and Gynecology, Shengjing Hospital of China Medical University, Shenyang, Liaoning, P.R. China

Received February 11, 2015; Accepted March 27, 2015

DOI: 10.3892/ijo.2015.2958

\begin{abstract}
Gestational choriocarcinoma is a high-grade malignant tumor. In this study, the effects of Dickkopf-1 (DKK1) on a human trophoblast cell line was examined by using both in vitro and in vivo assays. DKK1 was observed to induce apoptosis and inhibit proliferation in JEG3 and BeWo cells. Moreover, DKK1 suppressed tumor growth in established xenograft tumor models. In western blot assays, DKK1 was found to inhibit the Wnt/ $\beta$-catenin signaling pathway and active the mitochondrial apoptosis pathway. Overall, our study demonstrated the antitumor activity of DKK1 towards the JEG3 and BeWo cells. Valuable insight into the mechanisms mediated by DKK1 was obtained, potentially leading to the identification of novel treatments for gestational choriocarcinoma.
\end{abstract}

\section{Introduction}

Gestational choriocarcinoma usually arises from a prior molar pregnancy and occurs in 1 in 40,000 pregnancies (1). Improvement in treatment of gestational choriocarcinoma is required.

Dickkopf-1 is a $35-\mathrm{kDa}$ secreted protein that was originally characterized as a Wnt inhibitor (2). DKK1 plays a critical role in cell patterning, proliferation, and fate determination during embryogenesis (3). DKK1 was shown downregulated in many human cancers, such as gastric cancer, lung cancer, and breast cancer, indicating that it might act as a tumor suppressor (4-6). However, the role of DKK1 in tumor biology remains controversial. High expression of DKK1 is related to lymphatic metastasis and indicates poor prognosis in intrahepatic cholangiocarcinoma patients (7). The Wnt/ $\beta$-catenin signaling pathway is commonly dysregulated in various cancers (8-10). The signaling pathway can directly alter gene expression and is

Correspondence to: Professor Cai-Xia Liu, Department of Obstetrics and Gynecology, Shengjing Hospital of China Medical University, Heping District, Shenyang, Liaoning 110004, P.R. China

E-mail: liucx176@163.com

Key words: Dickkopf-1, trophoblast, apoptosis, Wnt, mitochondrial apoptosis pathway a key regulator of cell proliferation, apoptosis, differentiation, polarity, and migration $(11,12)$. DKK1 can directly bind to the Wnt ligands (secreted frizzled-related proteins, sFRPs) or by interacting with the low density lipoprotein receptor-related protein 5/6 (LRP) coreceptors, preventing binding of the Wnt proteins to the FRZ/LRP receptor complex (13). However, Kawano and Kypta (14) demonstrated that DKK1 suppressed the tumorigenicity of two human breast cancer cell lines that lack activated Wnt signaling.

In this study, the effects of treating trophoblast cell lines, JEG3 and BeWo, with human recombinant DKK1 protein were determined in vitro and in vivo. As expected, DKK1 reduced the proliferation of JEG3 and BeWo cells. Moreover, the cellular biological mechanisms of DKK1 were determined.

\section{Materials and methods}

Cell lines and culture conditions. Human choriocarcinoma cells, JEG-3 and BeWo (ATCC, Manassas, VA, USA) were maintained in Dulbecco's modified Eagle's medium (DMEM, Hyclone, Logan, UT, USA) supplemented with $10 \%$ heatinactivated FBS, $2 \mathrm{mM}$ glutamine, penicillin $(100 \mathrm{U} / \mathrm{ml})$ and streptomycin $(100 \mu \mathrm{g} / \mathrm{ml})$ at $37^{\circ} \mathrm{C}$ with $5 \% \mathrm{CO}_{2}$.

Methylation analysis. Genomic DNA was extracted and purified from cells using DNAzol (Invitrogen Life Technologies; Carlsbad, CA, USA) according to the manufacturer's protocol. The extracted DNA was modified by treatment with sodium bisulfite using the EpiTect Bisulfite kit (Qiagen, Hilden, Germany). The methylation status of the DKK1 gene was assessed using both methylation specific PCR (MSP) and bisulfate sequencing. The modified DNA was used as a template both for MSP and unmethylated-specific PCR (USP). The primer sequences for the methylated DKK1 gene were 5'-TTAAGGGGTCGGAATGTTTC-3' (sense) and 5'-CAC GAAACCGTACCGATTC-3' (antisense) and for the unmethylated allele were 5'-TTTTAAGGGGTTGGAATGTTTT-3' (sense) and 5'-CCACAAAACCATACCAATTCAAC-3' (antisense). The PCR products were separated in a $2 \%$ agarose gel with ethidium bromide and visualized under UV illumination. To examine the effect of demethylation, cells were incubated with medium containing $10 \mu \mathrm{M}$ 5-aza-2'-deoxycytidine (5-aza-dC, Sigma-Aldrich, Carlsbad, CA, USA) for $36 \mathrm{~h}$. Then DNA was isolated and MSP carried out as described above. 
Immunofluorescence. Cells were washed with PBS, fixed in $4 \%$ paraformaldehyde, permeabilized in $1 \%$ Triton X-100 for $15 \mathrm{~min}$ at room temperature and blocked with $5 \%$ bovine serum albumin in PBS for $1 \mathrm{~h}$. DKK1 was detected using anti-DKK1 (Santa Cruz, sc-25516) antibody for $1 \mathrm{~h}$ at room temperature. Cells were washed with PBS and incubated with the appropriate fluorophore-conjugated secondary antibody, Alexa Fluor ${ }^{\circledR} 594$ Donkey anti-rabbit $\operatorname{IgG}(\mathrm{H}+\mathrm{L})$, for $1 \mathrm{~h}$ at room temperature, washed with PBS, and mounted using Prolong anti-fade (Sigma).

Cell growth assay. Cells were seeded at 200 cells per well in 24-well tissue culture plates and incubated under normal culture conditions. After $24 \mathrm{~h}$, cells were treated with various concentrations of rhDKK1 protein (e.g., 0, 10, 50, 100 and $200 \mathrm{ng} / \mathrm{ml}$ for each). Plates were incubated for 3 weeks in a humidified incubator at $37^{\circ} \mathrm{C}$. Two weeks after seeding, colonies were stained with $0.05 \%$ crystal violet containing $50 \%$ methanol and counted. The colonies were counted in 4-5 random fields for each of the duplicate samples by using a microscope at x100 magnification.

Apoptosis detection. Cells were trypsinized, washed twice with cold PBS, and resuspended in $200 \mu \mathrm{l}$ binding buffer. Annexin V-FITC was added to a final concentration of $0.5 \mu \mathrm{g} / \mathrm{ml}$, according to the manufacturer's instructions (KeyGen, Nanjing, China). After 20-min incubation at room temperature in the dark, $400 \mu \mathrm{l}$ of binding buffer containing propidium iodide (PI, $50 \mu \mathrm{g} / \mu \mathrm{l})$ was added, and samples were immediately analyzed on a FACSCalibur flow cytometer (Becton-Dickinson Medical Devices, Shanghai, China).

Detection of mitochondrial transmembrane potential (MMP). The changes in the mitochondrial potential were detected by using 5,5',6,6'-tetrachloro-1,1',3,3' tetraethylbenzimidazolylcarbocyanine iodide/chloride (JC-1, KeyGen), a cationic dye that exhibits potential-dependent accumulation in mitochondria. These changes were indicated by fluorescence emission shift from red $(590 \mathrm{~nm})$ to green $(525 \mathrm{~nm})$ and analyzed on a flow cytometer (BD).

Invasion assays. Transwell chamber $(8-\mu \mathrm{M}$ pore size polycarbonate membrane, Cell Biolabs, San Diego, CA, USA) Matrigel-invasion assays were performed to detect the invasion of cells. Cells $(30,000)$ were placed in the upper chamber and allowed to invade for $24 \mathrm{~h}$. Ten fields of cells were acquired at x10 magnification and quantified. Relative invasion was expressed as a ratio of control cells.

In vivo antitumor effect. All animal studies were conducted by the Animal Care and Use Committee of China Medical University. Fifty NOD SCID mice (Institute of Animal Center, Chinese Academy of Sciences, Shanghai, China), male, aged 4-6 weeks, were used in the in vivo experiment for observing antitumor efficacy of DKK1. Tumor xenografts were established by subcutaneous inoculation of $3 \times 10^{7} \mathrm{JEG}-3$ cells into the back of mice. When tumors reached 5-7 $\mathrm{mm}$ in diameter, the mice were randomly divided into five groups (untreated, PBS, DKK1, DKK1+si-LGR6 \#1 and DKK1+si-LGR6 \#2). Mice were then intratumorally injected with $100 \mu \mathrm{l}$ of PBS,
DKK1, DKK1+si-LGR6 \#1 or DKK1+si-LGR6 \#2. Synthetic siRNA (100 nM) (si-LGR6) specifically targeting LGR6 (Invitrogen) were used to transfect cells using Oligofectamine (Invitrogen). The injections were repeated every two days. Tumor growth was monitored by periodic measurements with calipers. All animals were sacrificed five weeks post-treatment and tumors were dissected for pathological examination. Another 80 NOD SCID nude mice treated in the same way as described above and used to observe the survival time. The survival status of the mice was observed until the experiments were terminated for unacceptable tumor burden.

Enzyme-linked immunosorbent assay (ELISA). To measure the serum DKK1 concentration from mouse, a sandwich enzyme-linked immunosorbent assay (ELISA) was performed using DKK1 ELISA kit (R\&D Systems) according to its protocol.

Western blot analysis. Cells and tissues were harvested, washed twice with PBS, lysed on ice for $30 \mathrm{~min}$ in $100 \mu \mathrm{l}$ lysis buffer [120 mM NaCl, $40 \mathrm{mM}$ Tris ( $\mathrm{pH} \mathrm{8.0),} \mathrm{0.1 \%} \mathrm{NP-40]}$ and then centrifuged at $13,000 \mathrm{~g}$ for $15 \mathrm{~min}$. The supernatants were collected from the lysates and the protein concentration was determined. Aliquots of the lysates $(50 \mu \mathrm{g}$ of protein) were boiled for $5 \mathrm{~min}$ and electrophoresed using a $10 \%$ sodium dodecysulfate-polyacrylamide gel. The blots in the gels were transferred onto nitrocellulose membranes (Bio-Rad, Hercules, CA, USA), which were then incubated with primary antibodies. Axin2 (2151, 1:500) was purchased from Cell Signaling Technology (Beverly, MA, USA). LRP6 (sc-25317, 1:500), glycogen synthase kinase (GSK-3 $\beta$, sc-377213, 1:200), $\beta$-catenin (sc-7963, 1:200), Bax (sc-7480, 1:500), Bcl-xL (sc-8392, 1:200), Bcl-2 (sc-783, 1:500), phospho-Bcl-2 (Ser 87) (sc-16323, 1:200), $\beta$-tubulin (sc-5274, $1: 500)$ and $\beta$-actin (sc-103656, 1:1,000) antibodies were purchased from Santa Cruz Biotechnology (Santa Cruz, CA, USA). The nitrocellulose membranes were further incubated with secondary immunoglobulin-G-horseradish peroxidase conjugates. Immunostaining was detected using an enhanced chemiluminescence (ECL) system (Amersham Biosciences, Westborough, MA, USA).

In silico experiment. The interaction between DKK1 and LRP6 protein was analyzed by SYBYL-X 1.3 (Tripos International, St. Louis, MO, USA). The structure of DKK1 (PDB code: 3S8V) and LRP6 (PDB code: 3S8Z) protein were retrieved from the Protein Data Bank (http://www.rcsb.org).

Determination of the FRET efficiency in a confocal image. FRET measurements were performed on the confocal laser scanning microscope (Bio-Rad) as previously described (15). Donor signal I1 (excitation $=488 \mathrm{~nm}$, emission $=505-530 \mathrm{~nm}$ ), FRET signal $\mathrm{I} 2$ (excitation $=488 \mathrm{~nm}$, emission $>585 \mathrm{~nm}$ ), and acceptor signal I3 (excitation $=543 \mathrm{~nm}$, emission $>585 \mathrm{~nm}$ ) were collected.

Statistical analysis. Statistical analyses were carried out using GraphPad Prism 5.0 (GraphPad Software Inc., San Diego, CA, USA). Data were expressed as mean \pm standard deviation of three independent experiments performed in triplicate. Data 
A

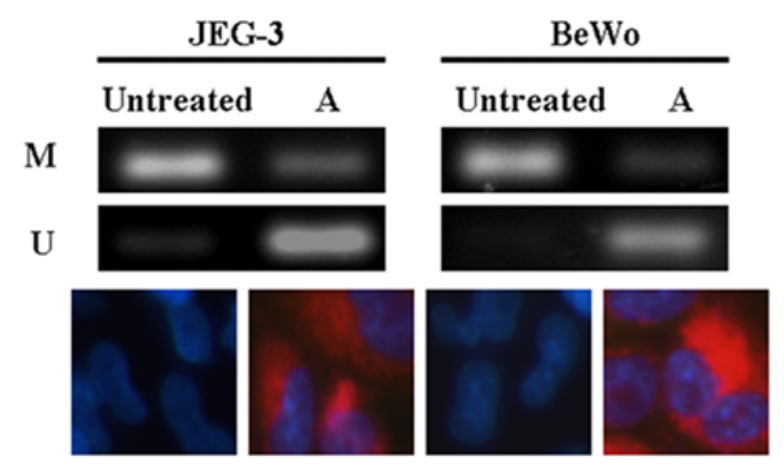

B
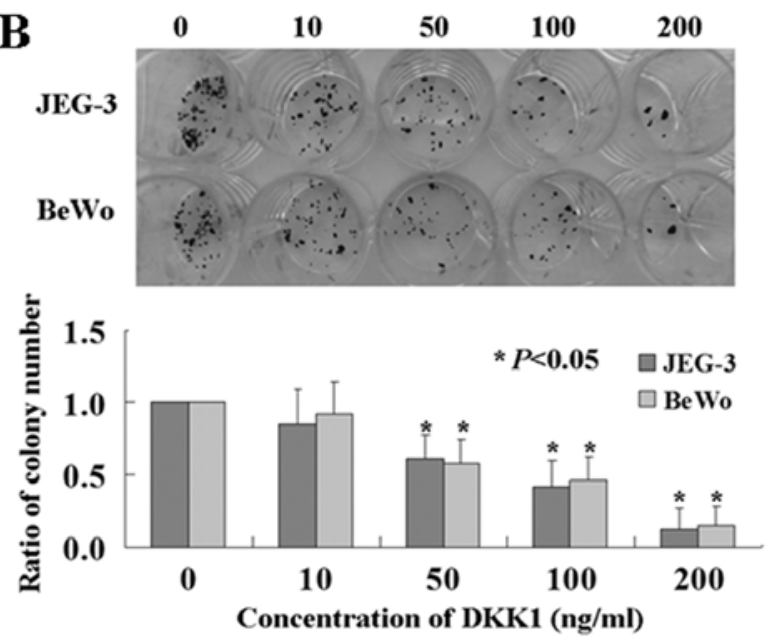

C
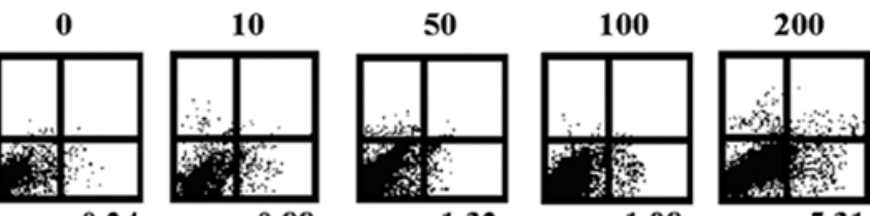

1.98
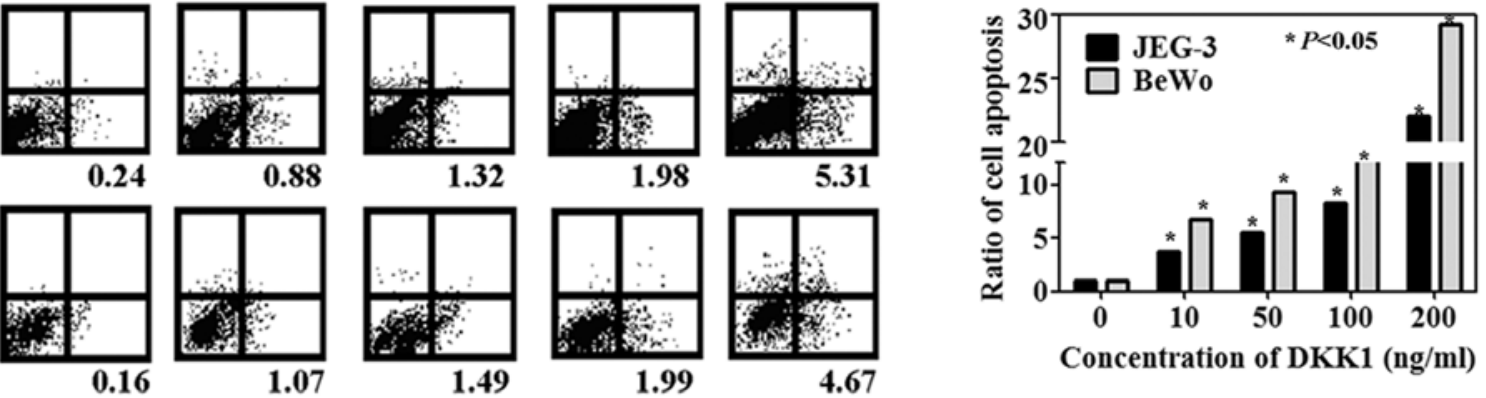
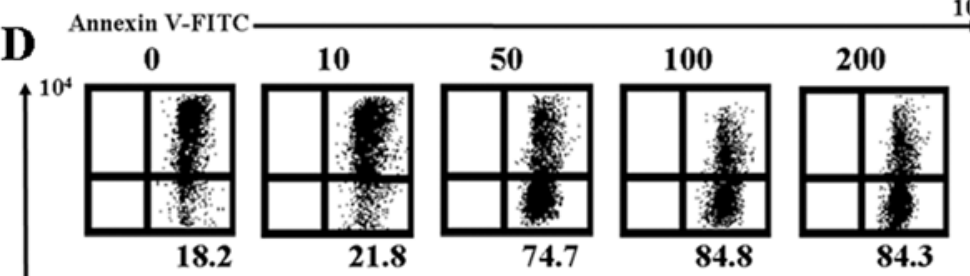

E
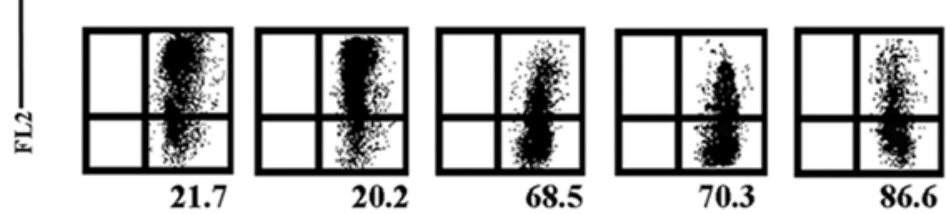

FL1 $10^{4}$
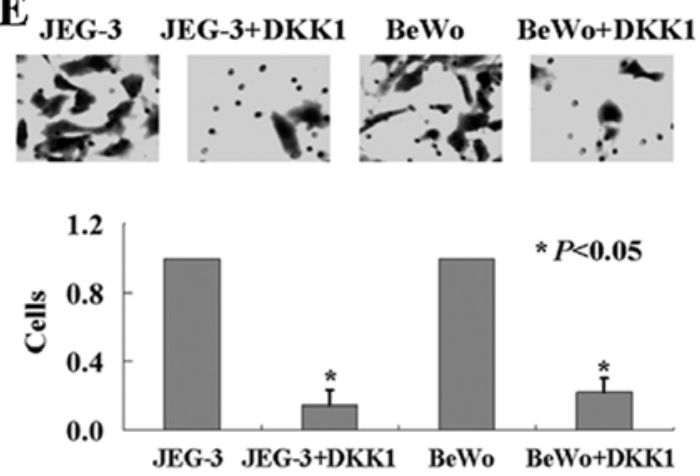

Figure 1. The antitumor roles of DKK1 in JEG3 and BeWo cells. (A) DKK1 promoter methylation in JEG3 and BeWo cells was attributed to low expression of DKK1. U, unmethylated; M, methylated; A, 5'-Aza-2'-deoxycytidine. (B) The ratio of growth inhibition of DKK1 on JEG3 and BeWo cells was determined by colony formation assay $(\mathrm{P}<0.05)$. (C) Apoptotic ratio of DKK1-treated cells was analyzed by Annexin V/PI double staining (P<0.05). (D) Mitochondrial membrane potential was analyzed by flow cytometry. (E) Cell invasion was determined by using Transwell assay.

comparisons in relation to control were performed by one-way ANOVA. The Kaplan-Meier method was used to estimate the probability of mouse survival. Differences were considered statistically significant at $\mathrm{P}$-value $<0.05$.

\section{Results}

DKK1 promoter methylation analysis. A correlation was observed between $D K K 1$ promoter methylation and decreased DKK1 mRNA levels in both JEG3 and BeWo cells (Fig. 1A). After the cells were treated with 5-aza-dC, we found that the DKK1 mRNA and protein expression was restored (Fig. 1A).
The roles of rhDKK1 protein in JEG3 and BeWo cells. Colony formation assay was used to detect cell viability. As shown in Fig. 1B, the proliferation rate of both JEG3 and BeWo cells were inhibited by rhDKK1 protein in a dosedependent manner $(\mathrm{P}<0.05)$. The $\mathrm{IC}_{50}$ values for JEG3 and BeWo cells were 83.4 and $97.3 \mathrm{ng} / \mathrm{ml}$, respectively. The results of Annexin V-FITC and PI double staining showed that the apoptotic ratio of the cells after DKK1 treatment was increased significantly in these cells (Fig. 1C, $\mathrm{P}<0.05$ ). Mitochondrial damage was indicated by the fluorescence emission shift from red to green. JEG3 and BeWo cells showed mitochondrial damage following DKK1 treatment 
$\mathbf{A}$

JEG-3

BeWo

A

$\begin{array}{llllllllll}0 & 10 & 50 & 100 & 200 & 0 & 10 & 50 & 100 & 200\end{array}$

LRP6 $\begin{array}{llllllllllll}1.00 & 0.86 & 0.58 & 0.31 & 0.19 & 1.00 & 0.88 & 0.44 & 0.42 & 0.16\end{array}$

Axin2

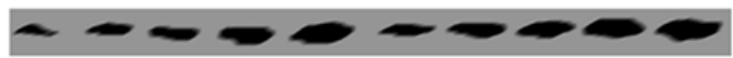

$\begin{array}{llllllllll}1.00 & 1.24 & 1.87 & 3.22 & 5.54 & 1.00 & 1.38 & 1.61 & 2.86 & 4.88\end{array}$

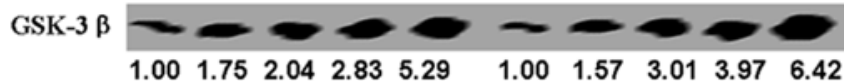

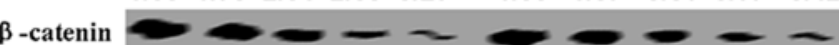

$\begin{array}{llllllllll}1.00 & 0.84 & 0.52 & 0.14 & 0.09 & 1.00 & 0.74 & 0.48 & 0.24 & 0.08\end{array}$

$\beta$-tubulin

$1.001 .08 \quad 0.971 .121 .06 \quad 1.001 .06 \quad 1.011 .061 .08$

B

JEG-3

BeWo

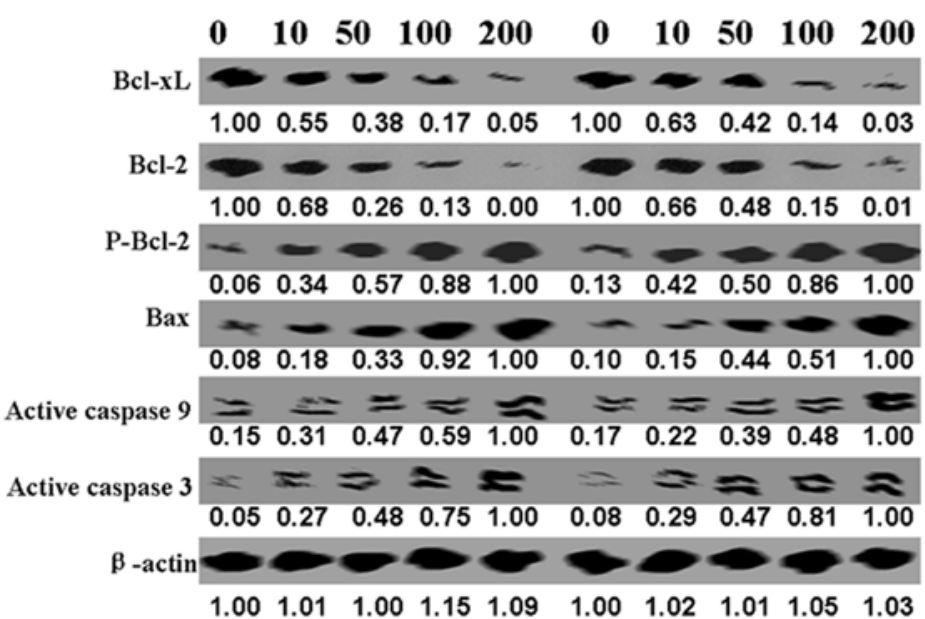

Figure 2. Western blot analysis of the Wnt signaling pathway and the mitochondrial apoptosis pathway. (A) Levels of LRP6, Axin2, GSK-3 and $\beta$-catenin from cell lysates were determined, respectively. $\beta$-tubulin was used as a control. (B) Bcl-2 and Bcl-xL, p-Bcl-2, Bax, active caspase- 9 and -3 were also detected by using western blot analysis. $\beta$-actin was used as a control.

A Untreated PBS DKK1 DKK1+si\#1 DKK1+si\#2 C
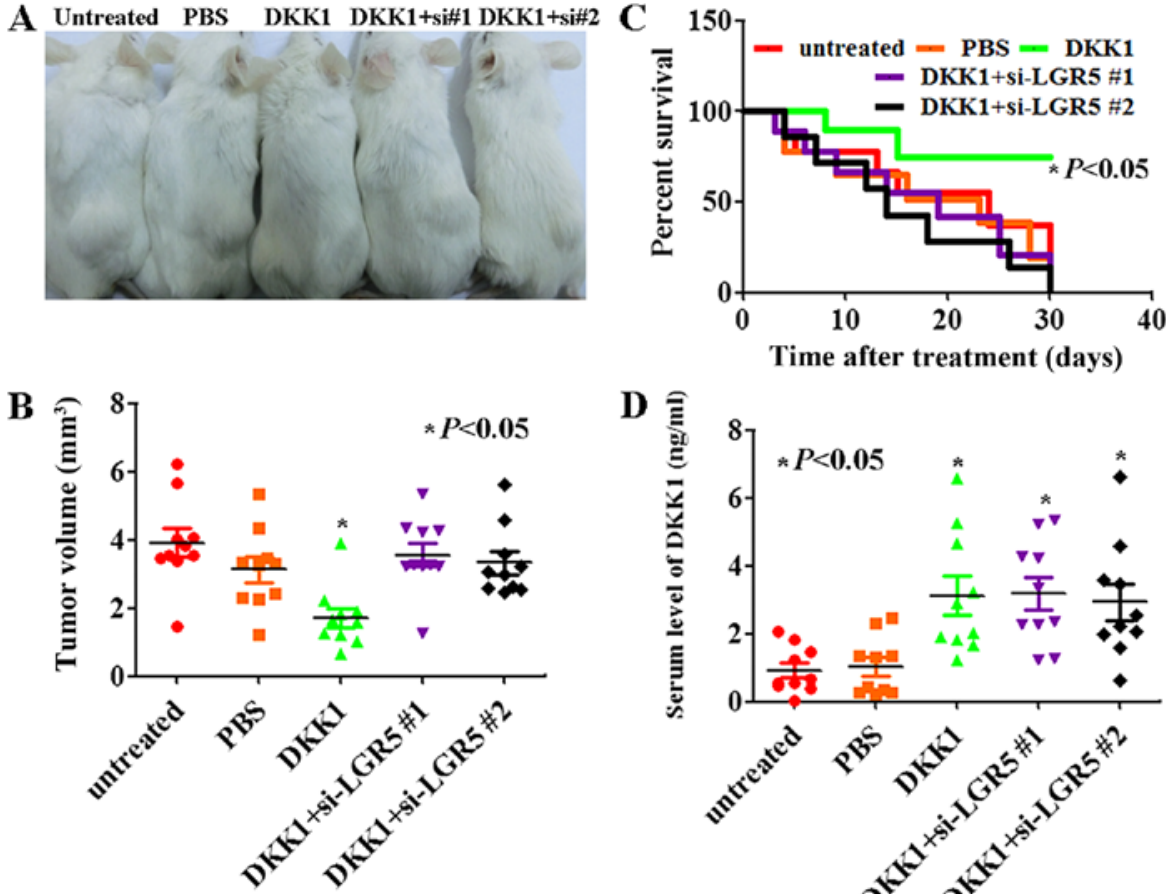

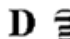

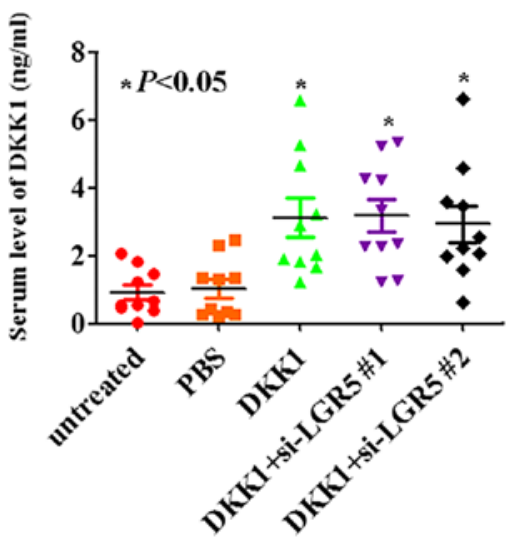

Figure 3. The role of DKK1 in xenograft mouse models. (A) Macroscopic appearance of subcutaneous tumors in each group described in Materials and methods. (B) Tumor volume of each group described in Materials and methods. (C) Kaplan-Meier survival curves of the groups described in Materials and methods. (D) Serum DKK1 levels from xenograft mouse models were measured using ELISA. 


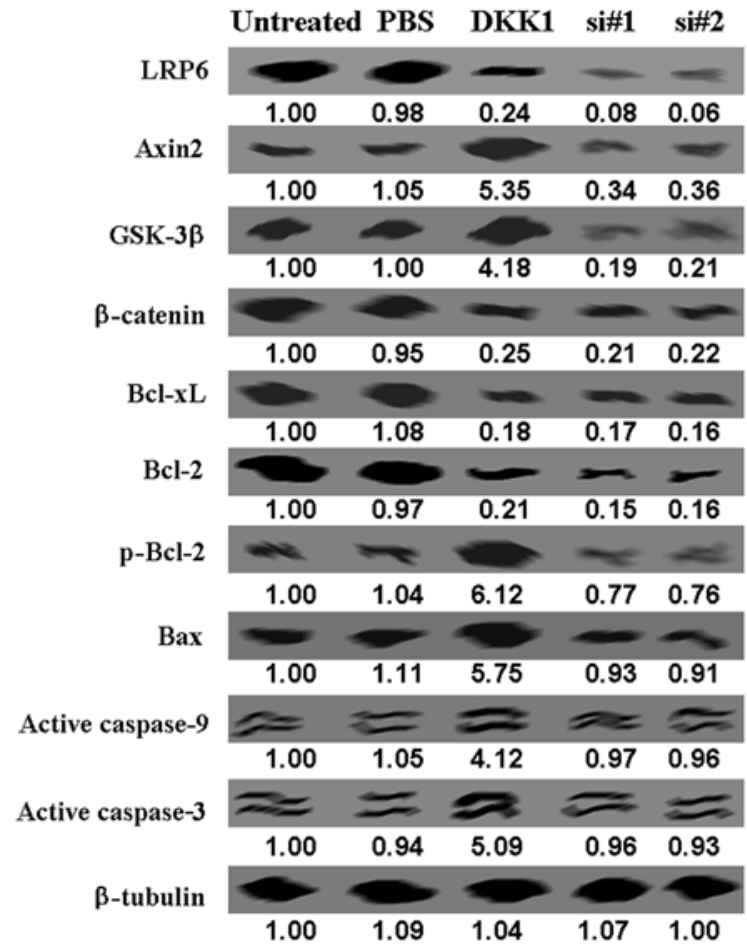

Figure 4. Western blot analysis of the Wnt signaling pathway and the mitochondrial apoptosis pathway. $\beta$-tubulin was used as a control.

(Fig. 1D). In addition, we found that significantly less cells migrated to the lower membrane compared with untreated ones (Fig. 1E, $\mathrm{P}<0.05$ ).

DKK1 inhibits the Wnt signaling pathway and induced the mitochondrial apoptosis pathway. Furthermore, we carried out western blot analysis to identify the mechanism of apoptosis induced by DKK1. We found that LRP6 and $\beta$-catenin protein levels were lower in treated cells than untreated ones, while Axin2 and GSK-3 protein levels were increased in the treated ones (Fig. 2A). Compared with untreated control, we found a decrease in $\mathrm{Bcl}-2$ and $\mathrm{Bcl}-\mathrm{xL}$ protein, and an increase in p-Bcl-2 and Bax protein levels in DKK1-treated cells (Fig. 2B). Active caspase-3 and -9 were also increased in DKK1-treated cells (Fig. 2B).

DKK1 inhibits tumor growth in mouse xenograft models. We next determined the antitumor properties of DKK1 in established xenograft tumor models. As shown in Fig. 3B, the tumor volume of DKK1-treated JEG-3 mice was less than untreated or PBS treated JEG-3 mice $(\mathrm{P}<0.05)$. In addition, the survival rate of mice with tumors treated with DKK1 was significantly improved (Fig. 3C, P<0.05). The serum levels of DKK1 in the mice treated with DKK1 were higher than that in untreated or PBS treated ones (Fig. 3D, P<0.05). Interestingly, DKK1 showed no effects on LRP6 knockdown JEG-3 cells (Fig. 3, $\mathrm{P}<0.05)$. We knocked down LRP6 expression in JEG-3 cells by using synthetic siRNA (si-LGR6) and noticed that the effect of DKK1 on Wnt signaling pathway and mitochondrial apoptosis pathway was offset by si-LGR6 (Fig. 4). These results indicated that DKK1 may cause its antitumor effect by LGR6 in JEG-3 cells.

DKK1 binds to LGR6 and inhibits the Wnt signaling pathway. We found that DKK1 was ab; e to bind to LGR6 by using the modeling software SYBYL-X 1.3 (Fig. 5B). Furthermore, we carried out FRET to identify the interaction between DKK1 and LGR6. To permit spectroscopic analyses of receptor assembly and function in the living cell, we tagged DKK1 protein with RFP and labeled LGR6 with GFP. The results

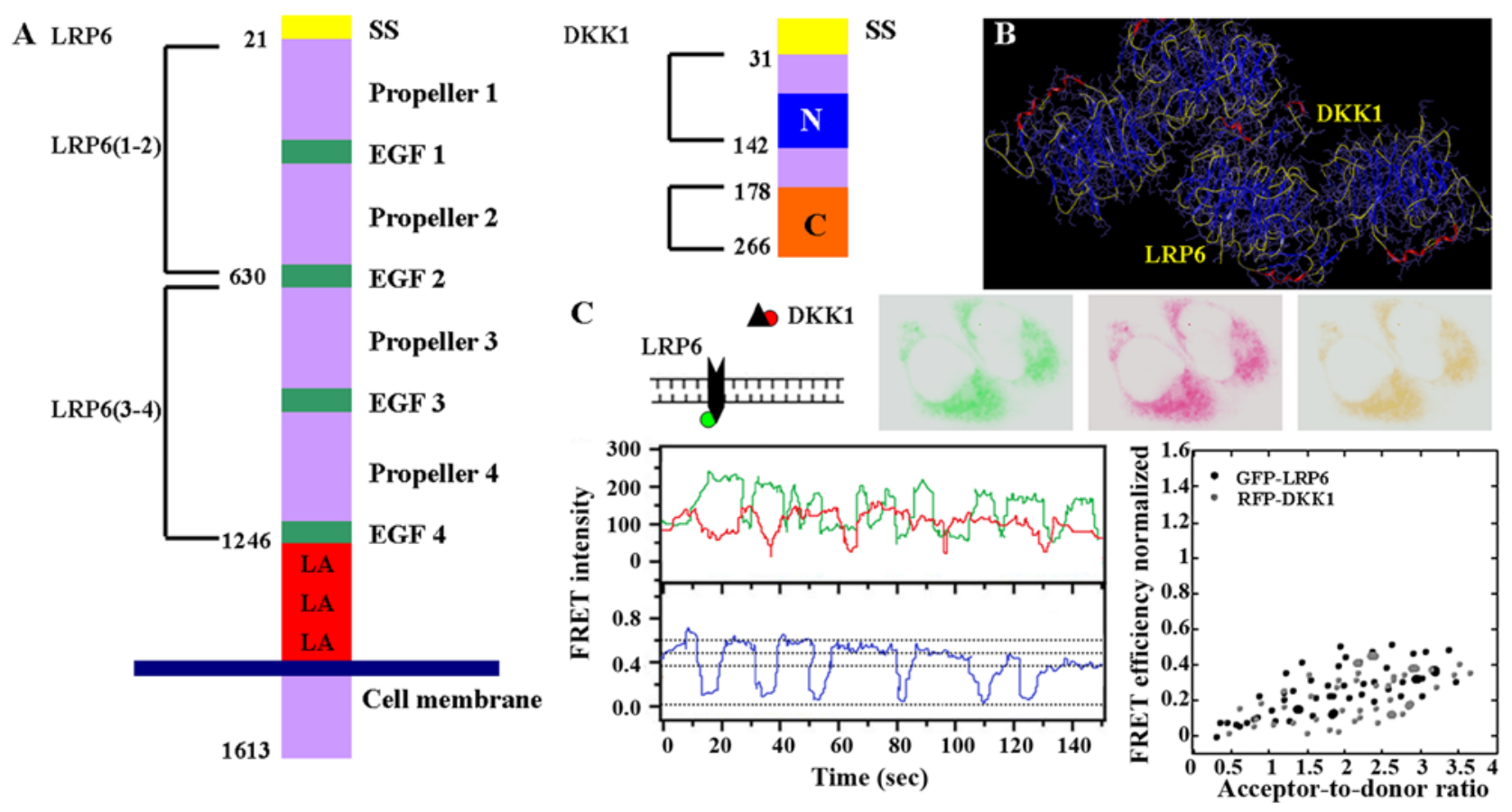

Figure 5. The interaction between DKK1 and LRP6. (A) Schematic model of DKK1 and LRP6 protein. (B) The interaction between DKK1 and LRP6 protein was analyzed by SYBYL-X 1.3. (C) The interaction between DKK1 and LRP6 protein was analyzed by FRET. 
A DKK1

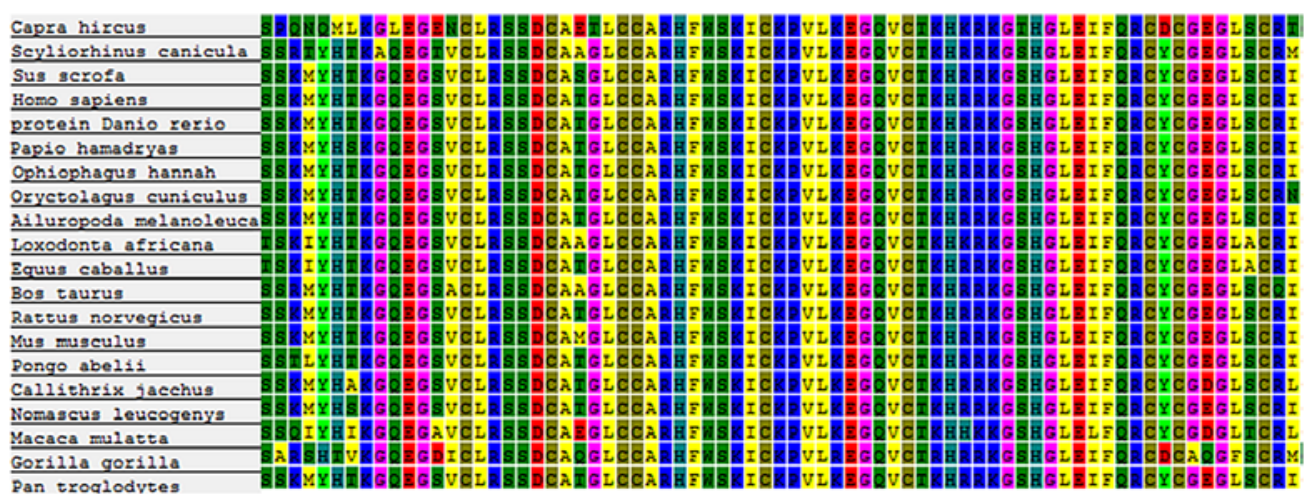

GI182889430|gb|AA/65086.1LDkk1_protein_Danio_renio

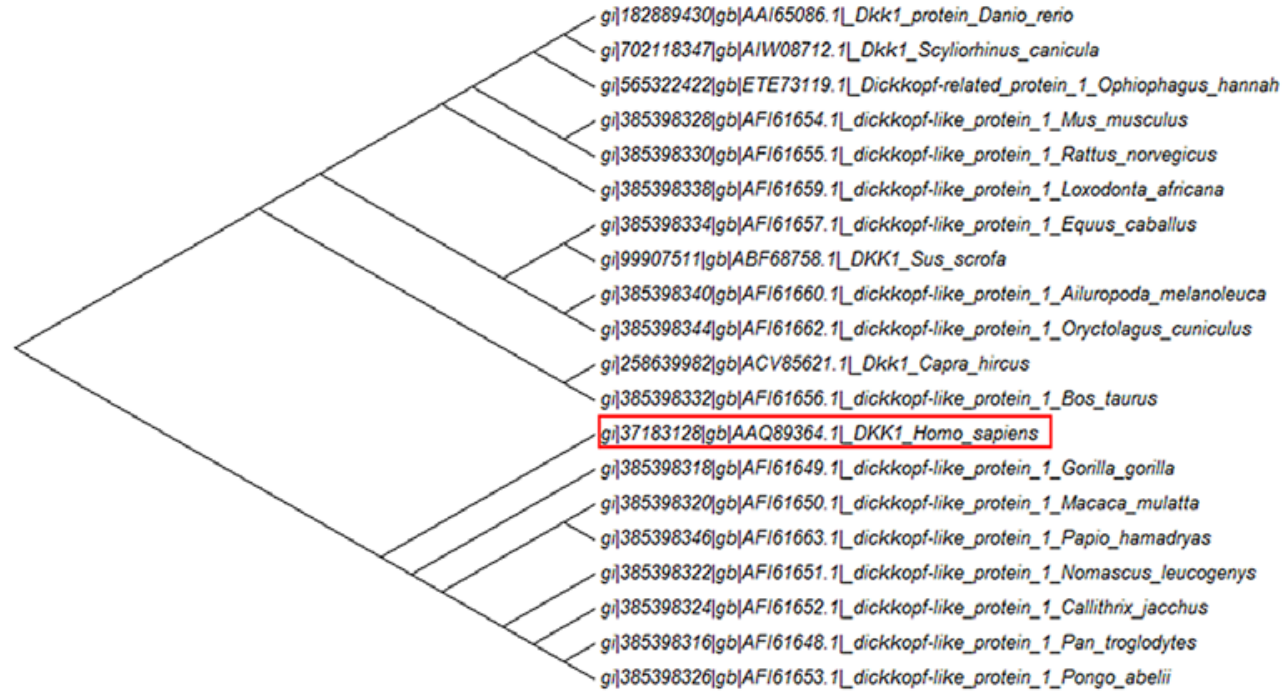

B LRP6

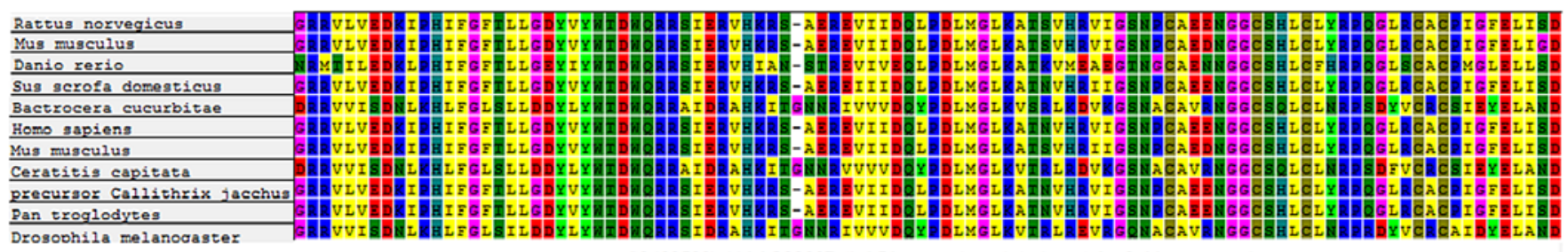

Drosobhila melanocastex

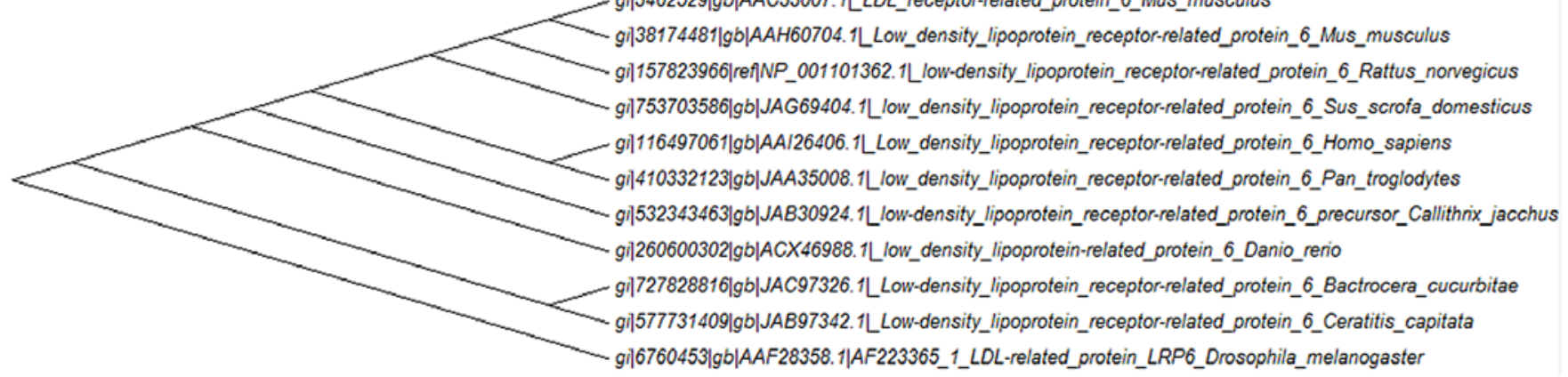

Figure 6. Phylogena and multiple alignment of DKK1 and LRP6. Conserved active site motifs of DKK1 (A) and LRP6 (B) from different evolutionary distinct supergroups. An evolutionary tree of DKK1 (A) and LRP6 (B) generated by the maximum likelihood analysis.

of FRET confirmed an almost linear increased donor (DKK1) and acceptor (LGR6) dimer (Fig. 5C). Furthermore, we carried out multiple sequence alignment and phylogenetic analysis. Additionally, we confirmed both the DKK1 and LGR6 as highly conserved proteins (Fig. 6), indicating that our results can be applied to other species.

\section{Discussion}

DKK-1 has been previously reported to be downregulated in human colon cancer for promoter hypermethylation (16). In our study, we also confirmed that decreased DKK1 in trophoblast tumor cell lines was related to promoter hypermethylation. 
The Wnt/ $\beta$-catenin signaling pathway plays a pivotal role in regulating cellular processes involved in development and differentiation (17). Aberrant Wnt/ $\beta$-catenin signaling is widely implicated in cancer, such as lung cancer (18), gastric cancer (19) and colorectal cancer (20). This signaling pathway is activated by the binding of a Wnt agonist to low density lipoprotein receptor (LDLR)-related protein 6 (LRP6) that are present at the cell surface (21). In the absence of Wnt signaling, GSK-3 is active and phosphorylates $\beta$-catenin in the scaffolding protein complex of adenomatous polyposis coli (APC) and Axin (22). Antagonists that interfere with Wnt ligand/ receptor interactions may therefore be potent cancer treatments (23). In this study, we also confirmed that DKK1 inhibited the proliferation of trophoblast tumor cells by suppressing the Wnt signaling pathway.

Furthermore, DKK1 was able to activate the mitochondrial apoptosis pathway in trophoblast tumor cells. DKK1 showed no effects on LRP6 knockdown trophoblast tumor cells. Our results indicated that the effects of DKK1 on mitochondria were through the Wnt signaling pathway. Activation of $\mathrm{Wnt} / \beta$ catenin signaling activates caspase- 3 and -9 and reduces the mitochondrial membrane potential (24). The anti-apoptotic $\mathrm{Bcl}-2$ protein is a target gene of the canonical $\mathrm{Wnt} / \beta$-catenin signaling pathway (25). Our results are consistent with the above previous studies.

In conclusion, the principal findings of our study are that: i) the antitumor roles of DKK1 in trophoblast tumor cells, ii) DKK1 induces apoptosis in trophoblast tumor cells by activating mitochondrial apoptosis pathway and suppressing the Wnt/ $\beta$-catenin signaling pathway, and iii) DKK1-mediated apoptosis is regulated by the expression of LRP6 in vivo and in vitro.

\section{Acknowledgements}

We thank Dr Yu Jian for his valuable comments and excellent technical assistance.

\section{References}

1. Milenković V, Lazović B, Mačvanski M, Jeremić K and Hrgović Z: Clinical outcome of a FIGO sage IV gestational choriocarcinoma. Case Rep Oncol 6: 504-507, 2013.

2. Bafico A, Liu G, Yaniv A, Gazit A and Aaronson SA: Novel mechanism of Wnt signalling inhibition mediated by Dickkopf-1 interaction with LRP6/Arrow. Nat Cell Biol 3: 683-686, 2001.

3. Ogoshi K, Kasamatsu A, Iyoda M, Sakuma K, Yamatoji M, Sakamoto Y, Ogawara K, Shiiba M, Tanzawa H and Uzawa K: Dickkopf-1 in human oral cancer. Int J Oncol 39: 329-336, 2011.

4. Gao C, Xie R, Ren C and Yang X: Dickkopf-1 expression is a novel prognostic marker for gastric cancer. J Biomed Biotechnol 2012: 804592, 2012

5. Li S, Qin X, Guo X, Cui A, He Y, Wei S, Wang X and Shan B: Dickkopf-1 is oncogenic and involved in invasive growth in non small cell lung cancer. PLoS One 8: e84944, 2013.

6. Kyvernitakis I, Rachner TD, Urbschat A, Hars O, Hofbauer LC and Hadji P: Effect of aromatase inhibition on serum levels of sclerostin and dickkopf-1, bone turnover markers and bone mineral density in women with breast cancer. J Cancer Res Clin Oncol 140: 1671-1680, 2014.
7. Shi RY, Yang XR, Shen QJ, Yang LX, Xu Y, Qiu SJ, Sun YF, Zhang X, Wang Z, Zhu K, et al: High expression of Dickkopfrelated protein 1 is related to lymphatic metastasis and indicates poor prognosis in intrahepatic cholangiocarcinoma patients after surgery. Cancer 119: 993-1003, 2013.

8. Xu W, Wang Z, Zhang W, Qian K, Li H, Kong D, Li Y and Tang Y: Mutated K-ras activates CDK8 to stimulate the epithelial-to-mesenchymal transition in pancreatic cancer in part via the $\mathrm{Wnt} / \beta$-catenin signaling pathway. Cancer Lett 356B: 613-627, 2015.

9. Tong X, Li L, Li X, Heng L, Zhong L, Su X, Rong R, Hu S, Liu W, Jia B, et al: SOX10, a novel HMG-box-containing tumor suppressor, inhibits growth and metastasis of digestive cancers by suppressing the Wnt/ $\beta$-catenin pathway. Oncotarget 5: 10571-10583, 2014.

10. Liu H, Yan ZQ, Li B, Yin SY, Sun Q, Kou JJ, Ye D, Ferns K, Liu HY and Liu SL: Reduced expression of SOX7 in ovarian cancer: A novel tumor suppressor through the Wnt/ $\beta$-catenin signaling pathway. J Ovarian Res 7: 87, 2014.

11. Apte U, Zeng G, Thompson MD, Muller P, Micsenyi A, Cieply B, Kaestner KH and Monga SP: beta-catenin is critical for early postnatal liver growth. Am J Physiol Gastrointest Liver Physiol 292: G1578-G1585, 2007.

12. Nejak-Bowen K and Monga SP: Wnt/beta-catenin signaling in hepatic organogenesis. Organogenesis 4: 92-99, 2008.

13. Mikheev AM, Mikheeva SA, Maxwell JP, Rivo JV, Rostomily R, Swisshelm K and Zarbl H: Dickkopf-1 mediated tumor suppression in human breast carcinoma cells. Breast Cancer Res Treat 112: 263-273, 2008.

14. Kawano Y and Kypta R: Secreted antagonists of the Wnt signalling pathway. J Cell Sci 116: 2627-2634, 2003.

15. Vámosi G, Baudendistel N, von der Lieth CW, Szalóki N, Mocsár G, Müller G, Brázda P, Waldeck W, Damjanovich S, Langowski J, et al: Conformation of the c-Fos/c-Jun complex in vivo: A combined FRET, FCCS, and MD-modeling study. Biophys J 94: 2859-2868, 2008

16. González-Sancho JM, Aguilera O, García JM, Pendás-Franco N, Peña C, Cal S, García de Herreros A, Bonilla F and Muñoz A: The Wnt antagonist DICKKOPF-1 gene is a downstream target of beta-catenin/TCF and is downregulated in human colon cancer. Oncogene 24: 1098-1103, 2005.

17. Chien AJ, Conrad WH and Moon RT: A Wnt survival guide: From flies to human disease. J Invest Dermatol 129: 1614-1627, 2009.

18. Xu X, Kim JE, Sun PL, Yoo SB, Kim H, Jin Y and Chung JH: Immunohistochemical demonstration of alteration of $\beta$-catenin during tumor metastasis by different mechanisms according to histology in lung cancer. Exp Ther Med 9: 311-318, 2015.

19. Cui J, Xi H, Cai A, Bian S, Wei B and Chen L: Decreased expression of Sox7 correlates with the upregulation of the Wnt/ $\beta$-catenin signaling pathway and the poor survival of gastric cancer patients. Int J Mol Med 34: 197-204, 2014.

20. Silva AL, Dawson SN, Arends MJ, Guttula K, Hall N, Cameron EA, Huang TH, Brenton JD, Tavaré S, Bienz M, et al: Boosting Wnt activity during colorectal cancer progression through selective hypermethylation of Wnt signaling antagonists. BMC Cancer 14: 891, 2014.

21. Polakis P: Wnt signaling and cancer. Genes Dev 14: 1837-1851, 2000.

22. Kitagawa M, Hatakeyama S, Shirane M, Matsumoto M, Ishida N, Hattori K, Nakamichi I, Kikuchi A, Nakayama K and Nakayama K: An F-box protein, FWD1, mediates ubiquitindependent proteolysis of $\beta$-catenin. EMBO J 18: 2401-2410, 1999.

23. Lee JS, Hur MW, Lee SK, Choi WI, Kwon YG and Yun CO: A novel sLRP6E1E2 inhibits canonical Wnt signaling, epithelialto-mesenchymal transition, and induces mitochondria-dependent apoptosis in lung cancer. PLoS One 7: e36520, 2012.

24. Ming M, Wang S, Wu W, Senyuk V, Le Beau MM, Nucifora G and Qian Z: Activation of $\mathrm{Wnt} / \beta$-catenin protein signaling induces mitochondria-mediated apoptosis in hematopoietic progenitor cells. J Biol Chem 287: 22683-22690, 2012.

25. Jaeger A, Baake J, Weiss DG and Kriehuber R: Glycogen synthase kinase-3beta regulates differentiation-induced apoptosis of human neural progenitor cells. Int J Dev Neurosci 31: 61-68, 2013. 